\section{Plant Display Board Sells Good Management}

Robert F. PEarson, Jr. Soil Conservation Service, U.S.D.A., Benavides, Texas

In Benavides, Texas, the Soil Conservation Service technicians assigned to the Agua Poquita Soil Conscrvation District have hit upon an effective way to help livestockmen understand the value of conservation range management.

They planted, grew and "managed" a locally used grass (buffelgrass, Pennisetum ciliare) under conditions approaching those of grazing use.

From a service station they obtained 40-gallon grease drums, cleaned them and, after punching holes in the bottoms for drainage, filled them with sandy loam. They supplied enough water to bring the soil moisture to field capacity.

They planted the grass seeds in each drum on April 1, 1960, and cov- ered the soil with hay mulch to prevent rapid surface drying. They thinned the seedlings to three to each drum when the plants were three inches tall. When the grass was six inches high, the technicians clipped the plants in the first drum to a height of four inches. They repeated this each time about one inch of grass had regrown. This was to reflect overuse under range conditions. The clipped material was retained in a paper bag marked to correspond to the drum.

Grass in the second drum was clipped to a height of six inches each 21 days. This was intended to represent the effect of rotation grazing. These clippings also were retained. The grass in the third drum was clipped continuously to a height of eight inches each time an inch of new growth appeared. Local technical guides show this as a standard for proper use of buffelgrass.

The grass in the fourth drum was

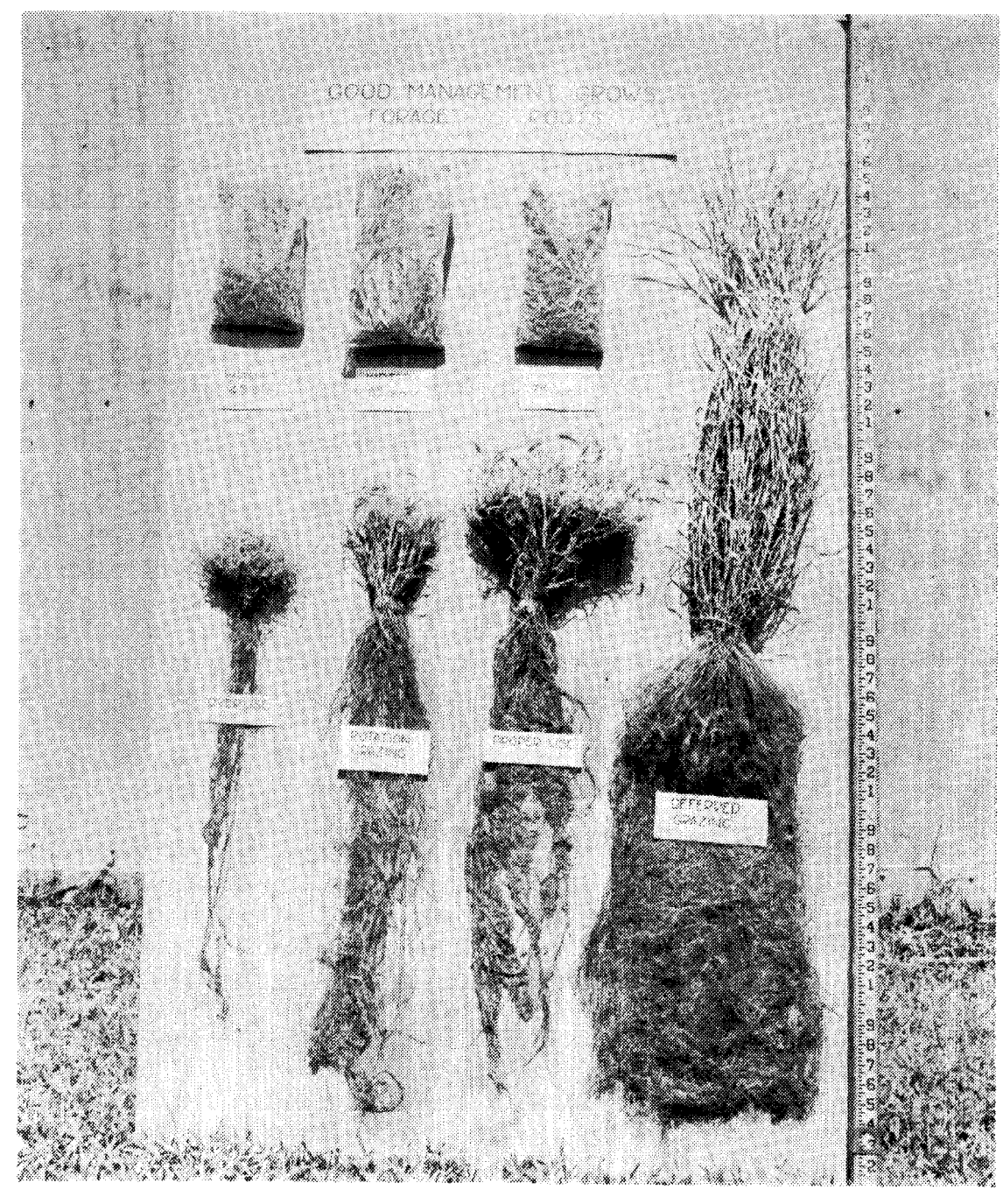

